\title{
Sol-Gel Relative Humidity Sensors: Impact of Electrode Geometry on Performance in Soil Suction Measurements
}

\author{
Rafaela Cardoso ${ }^{1,2 *}$, Gabriele Sarapajevaite ${ }^{3}$, Oleksandr Korsun ${ }^{3}$, Susana Cardoso ${ }^{1,3}$, \\ Laura Ilharco 1,4 \\ ${ }^{1}$ Instituto Superior Técnico (IST), Universidade de Lisboa, Lisbon, Portugal \\ ${ }^{2}$ Civil Engineering Research Innovation and Sustainability (CERIS), Institute of Construction, Structures and Territory of IST \\ (ICIST), Lisbon, Portugal \\ ${ }^{3}$ INESC-MN Microsystems and Nanotechnologies, Lisbon, Portugal \\ ${ }^{4}$ CQFM Centro de Química-Física Molecular, Instituto Superior Técnico (IST), Lisbon, Portugal \\ Email: ^rafaela@civil.ist.utl.pt
}

How to cite this paper: Cardoso, R., Sarapajevaite, G., Korsun, O., Cardoso, S. and Ilharco, L. (2017) Sol-Gel Relative Humidity Sensors: Impact of Electrode Geometry on Performance in Soil Suction Measurements. Journal of Sensor Technology, 7, 123.

https://doi.org/10.4236/jst.2017.71001

Received: January 19, 2017

Accepted: March 27, 2017

Published: March 30, 2017

Copyright $\odot 2017$ by authors and Scientific Research Publishing Inc. This work is licensed under the Creative Commons Attribution International License (CC BY 4.0).

http://creativecommons.org/licenses/by/4.0/

\begin{abstract}
This paper describes the experimental procedure followed to fabricate and validate sol-gel based RH sensors which will be incorporated in soil specimens for standard laboratorial tests. It is the first time such sensors were used for soil suction measurement. They are microfabricated relative humidity sensors (footprint area $11,000 \mu \mathrm{m} \times 22,000 \mu \mathrm{m}$ ) operating based on changes in electrical resistivity detected by a cerium doped silica titania film deposited using a sol-gel technique. Their design required gathering experts in several engineering specialties. The working principle of the sensors is based on water vapour equilibrium between the air in the soil and in the sol-gel pores, due to the contact between the two porous materials. The spacing between interdigitated aluminium electrodes was optimized to improve the sensing properties of the sol-gel. The calibration of the different prototypes was done against compacted clay, varying the spacing between 100 and $700 \mu \mathrm{m}$. The sensors were also incorporated in soil samples for suction measurement during wetting and drying paths. They were validated by comparing the readings with those from a water dew point potentiometer. From this study it was possible to determine the optimum electrodes spacing of $200 \mu \mathrm{m}$. Error was explained by sol-gel heterogeneity effect and by the resolution of the sensing area provided by the electrodes spacing. When comparing with other sensors operating inside soil specimens in standard laboratorial tests, these sol-gel sensors extend the operation range available with the alternative technologies: while conventional tensiometers measure suction ranges from 0 to $1.8 \mathrm{MPa}$, our sensors demonstrate
\end{abstract}


good results between 1 to $10 \mathrm{MPa}$ (and higher).

\section{Keywords}

Microfabricated Interdigitated Electrodes, Humidity Sensors, Suction, Unsaturated Soils

\section{Introduction}

Microfabricated relative humidity sensors (footprint area 11,000 $\mu \mathrm{m} \times 22,000 \mu \mathrm{m}$ ) operating based on changes in electrical resistivity detected by a cerium doped silica titania film deposited using a sol-gel technique, which was used for the first time to incorporate in soil specimens for suction measurement. For simplification, they are named in this paper as sol-gel sensors. Their design required gathering experts in several engineering specialties (Geotechnics, Physics, Electronics and Chemistry). The working principle of these sensors is based on the water vapour equilibrium between the air in the soil and in the sol-gel pores, due to the contact between the two porous materials.

The sensors developed are small sensors conceived to be incorporated inside laboratory testing cells for monitoring water transport during load application. This knowledge has several engineering applications where the relative humidity of deformable porous media must be known. In geotechnical engineering, such knowledge is important mainly for predicting deformations caused by wetting or drying, which is fundamental to study soil-atmosphere interaction and slope instability, and for developing tools to model unsaturated flow of water, gas and contaminants in both liquid and gas phases. In all cases the key parameter to measure is the degree of saturation (volume of water in the volume of voids), which is associated to the amount of water presented in the soil, or its water content. This degree of saturation must then be converted into suction because this is the corresponding stress to be used in constitutive modeling of unsaturated soils behaviour [1].

From thermodynamics, suction translates the water potential in soils and therefore can be related with relative humidity (RH) in the soil pores air. In total suction, $\Psi$ is related with relative humidity through Kelvin law [1],

$$
\Psi=-\frac{R T \rho}{M} \ln (R H)
$$

where $M$ is the molecular mass of water $(18.016 \mathrm{~kg} / \mathrm{kmol}), \rho$ is the density of pure water $\left(998 \mathrm{~kg} / \mathrm{m}^{3}\right.$ at $\left.293 \mathrm{~K}=20^{\circ} \mathrm{C}\right), R$ is the gas constant $\left(8.314 \mathrm{~J} / \mathrm{mol}^{-1} \cdot \mathrm{K}^{-1}\right)$ and $T$ is the absolute temperature.

Several RH sensors have been reported, based on thin film ceramics $\left(\mathrm{MgAl}_{2} \mathrm{O}_{4}\right.$, $\mathrm{MgFe}_{2} \mathrm{O}_{4}, \mathrm{Fe}_{2} \mathrm{O}_{3}$ or composite oxides with $\mathrm{TiO}_{2}$ ), as well as thick film sensors (pure alumina or incorporating $\mathrm{TiO}_{2}$ and $\mathrm{SnO}_{2}$ ), other ceramic sensors [2] [3], polymer sensors [4] and sensors with sol-gel films [5] [6] [7] [8]. The RH sen- 
sors investigated in this work are sol-gel resistive sensors. They were developed with the purpose to be incorporated in soil specimens during standard laboratorial tests, therefore they should be small, have fast response (in the order of minutes), low capacitance and low hysteresis. As far as we know, this is the first time sol-gel sensors are used in soils.

Several sensors are commercially available for local measurement of water in soils, most of them measuring water content or relative humidity [1]. These parameters allow estimating suction. Table 1 presents a synthesis of the existing sensors for soil suction, water content and relative humidity measurement. Additional information about their size and operation range is also included but further details can be found in the work of Tarantino et al. [9]. It can be seen that the large majority of the existing sensors are very large and therefore their incorporation inside soil samples (standard dimensions are disks with $2 \mathrm{~cm}$ height and 5 to $7 \mathrm{~cm}$ diameter, or cylinders with height double of the diameter and diameter ranging between 5 and $10 \mathrm{~cm}$ ) is impossible because it is too destructive, or their operation range is very small.

Amongst the existing sensors specifically developed for soil suction measurement, only the tensiometers [9] [10] [11] have been incorporated in soil specimens during standard laboratory tests with good results. However they have limited suction measurement ranges and are relatively large. There was a recent

Table 1. Most common sensors used in soils for measure or estimate soil suction.

\begin{tabular}{|c|c|c|c|c|c|}
\hline $\begin{array}{l}\text { Parameter } \\
\text { measured }\end{array}$ & Name & Size & $\begin{array}{l}\text { Response } \\
\text { time }\end{array}$ & Range (MPa) & $\begin{array}{c}\text { Compatibility with testing } \\
\text { equipment }\end{array}$ \\
\hline Suction & $\begin{array}{l}\text { Tensiometers } \\
\text { (agriculture) }\end{array}$ & $\begin{array}{l}\text { The smallest are } 5 \mathrm{~mm} \text { diameter pipes, } 10 \\
\qquad \mathrm{~cm} \text { long }\end{array}$ & Minutes & 0.1 to 0.8 & Too long \\
\hline suction & Tensiometers & $\begin{array}{l}\text { Cylinders } 1 \mathrm{~cm} \text { diameter } 2 \mathrm{~cm} \text { height, plus } \\
\text { cables }\end{array}$ & Minutes & 0.5 to 1.8 & $\begin{array}{l}\text { Placed in the top or } \\
\text { bottom of the cells }\end{array}$ \\
\hline 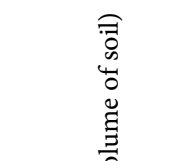 & Filter paper & $\begin{array}{l}\text { Small pieces of paper cut with } \\
\text { variable dimensions }\end{array}$ & Months & 0 to 1000 & $\begin{array}{l}\text { Can be placed inside soil } \\
\text { samples but do not allow } \\
\text { continuous } \\
\text { measurements }\end{array}$ \\
\hline 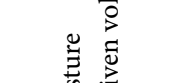 & Gypsum blocks & $\begin{array}{l}\text { Cylinders } 1 \mathrm{~cm} \text { diameter } \\
2 \mathrm{~cm} \text { height, plus cables }\end{array}$ & 24 hours & 0 to 0.2 & $\begin{array}{l}\text { Placed in the top or } \\
\text { bottom of the cells }\end{array}$ \\
\hline 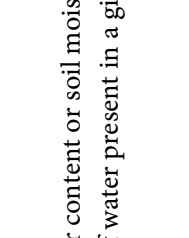 & $\begin{array}{c}\text { Electromagnetic } \\
\text { sensors: Frequency } \\
\text { Domain Reflectometer } \\
\text { (FDR) and Time } \\
\text { Domain Reflectometer } \\
\text { (TDR) probes }\end{array}$ & $\begin{array}{l}\text { Two metallic needles, } \\
2 \text { to } 10 \mathrm{~cm} \text { long, plus cables }\end{array}$ & Minutes & $\begin{array}{l}\text { Depends on soil type, } \\
\text { in general } 0-1.5\end{array}$ & Too long \\
\hline 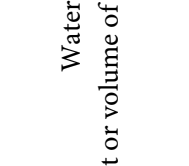 & $\begin{array}{l}\text { Electrical } \\
\text { resistive sensors }\end{array}$ & $\begin{array}{c}\text { Plates } \\
\text { ( } 5 \mathrm{~mm} \text { large and } 5 \mathrm{~cm} \text { long are the smallest) } \\
\text { or disks ( } 2 \mathrm{~cm} \text { diameter) with variable } \\
\text { dimensions. Thickness is } 2 \text { to } 3 \mathrm{~mm}\end{array}$ & Minutes & $\begin{array}{l}\text { Depends on soil type, } \\
\text { in general } 0-1.5\end{array}$ & Too large \\
\hline $\begin{array}{l}\frac{1}{60} \\
\frac{0}{20} \\
3\end{array}$ & Thermal sensors & Like the resistive sensors & Minutes & $\begin{array}{l}\text { Depends on soil type, } \\
\text { in general } 0-1.5\end{array}$ & Too large, dry the soil \\
\hline $\begin{array}{c}\text { Relative } \\
\text { humidity }(\mathrm{RH})\end{array}$ & $\begin{array}{l}\text { Resistive and thermal } \\
\text { sensors }\end{array}$ & $\begin{array}{l}\text { Like the water content resistivity and } \\
\text { thermal sensors. The difference is mainly in } \\
\text { the output provided by the equipment }\end{array}$ & Minutes & $\begin{array}{l}\text { Depends on soil type, } \\
\text { in general } 0 \text { to } 200 \text { in } \\
\text { theory, } \mathrm{RH} \text { between } \\
0 \% \text { and } 100 \%\end{array}$ & Too large or too long \\
\hline
\end{tabular}


attempt to miniaturize tensiometers [12] and their operation range was extended, however these new tensiometers were not tested in soils. For this reason the development of improved sol-gel sensors for being used in soils, compatible with a miniaturization trend, offer novel advantages.

The sensors developed in this research are sol-gel sensors inspired in the work of Kozhukharov et al. [5] [6] and extended further to be integrated with glass substrates and interdigitated aluminium electrodes defined with optimized spacing, matching the porosity of the tested soil specimens. The innovative aspect of this research is the validation of sol-gel based $\mathrm{RH}$ sensors for soils for the first time, adding to the fact that the final sensors are small enough to be incorporated in soil specimens for standard laboratorial tests, therefore minimizing soil disturbance. In addition, they increase the size of the suction interval measured at the present with the existing sensors (see Table 1).

The working principle of the sensors is briefly described in this paper, together with their working specifications. The description of the calibration curves obtained against compacted clay using five different electrode spacing is also included. After calibration, the sensors were then incorporated in compacted clay samples for suction measurement during wetting and drying cycles. This procedure corresponds to determine the water retention curve of the soil. This curve was also measured using a water dewpoint device, a laboratory equipment used for suction measurement of small soil samples. The comparison between the readings using both devices allowed validating the sensors operation in soils. In addition, it allowed to assess the impact of the contact between the sensing layer (sol-gel) and provided valid indication on the optimum geometry and mounting configuration to be used in integrated sensors for humidity measurements on soil.

\section{Sensors Description}

\subsection{Working Principle}

The sensors were developed to be incorporated in soils for suction measurement during standard laboratorial tests. Their main specifications were:

- Small size (flat and easy to be inserted in the soil, minimizing disturbance);

- Suction measurement range between $1 \mathrm{MPa}$ and $10 \mathrm{MPa}$ (99\% and 93\% of relative humidity for $21^{\circ} \mathrm{C}$, error $\pm 2.3 \%$ );

- Accuracy (error below 5\%) and low hysteresis;

- Fast response (in the order of minutes).

The sensor developed is a sol-gel resistive sensor microfabricated in clean room environment to achieve small dimensions with precision. The electrodes are covered by a Cerium doped silica-titania film deposited using a sol-gel technique. This is a porous coating, which is responsible for the required sensor sensitivity to water, because the water molecules are adsorbed by the sol-gel layer and therefore the electrical conductivity of this material increases [6]. The quantity of water molecules available for detection depends on the local relative humidity, 
which will be the same as the surrounding soil once equilibrium is reached. This equilibrium process, illustrated in Figure 1, involves the migration of water mainly in gas phase. Chemical effects were disregarded because, if they exist, they would affect all sensors in the same manner and therefore the comparison of their performance considering the different electrodes spacing continues valid.

The analysis of the water transfer mechanisms between the soil and the sol-gel is out of the scope of this paper. Identical mechanisms and transfer equilibrium time are assumed to be independent from the electrodes spacing because the sol-gel films in contact with the soil and its thickness is the same.

\subsection{Electrodes}

The sensors investigated comprise a set of interdigitated electrodes microfabricated in a clean room environment. A $300 \mathrm{~nm}$-thick aluminium $\left(\mathrm{Al}_{98.5} \mathrm{Si}_{1} \mathrm{Cu}_{0.5}\right)$ thin film was first deposited on a glass substrate by magnetron sputtering (Nordiko 7000 tool). The film was protected with a $30 \mathrm{~nm}$-thick TiWN anticorrosion layer, following the protocol for microelectronic device metallic interconnectors. The $100 \mu \mathrm{m}$ wide interdigitated electrodes were defined by direct laser lithography, followed by pattern transfer by wet etching. Figure 2(a) shows the geometry of the sensors fabricated. Several electrode spacing were tested $(100,200,300$, 500 and $700 \mu \mathrm{m}$ ), to assess on the geometry that would promote their best response in terms of sensitivity and hysteresis. Electrodes length is $8500 \mu \mathrm{m}$. Total sensor footprint area is $11,000 \mu \mathrm{m} \times 22,000 \mu \mathrm{m}$ and overall thickness is around $800 \mu \mathrm{m}$. The final device was them assembled with electrical wires, bond with silver paint, cured at $40^{\circ} \mathrm{C}$ overnight. The connection regions were fully covered with silicone, for complete sealing of the contacts during further processing with sol-gel and soil contact.

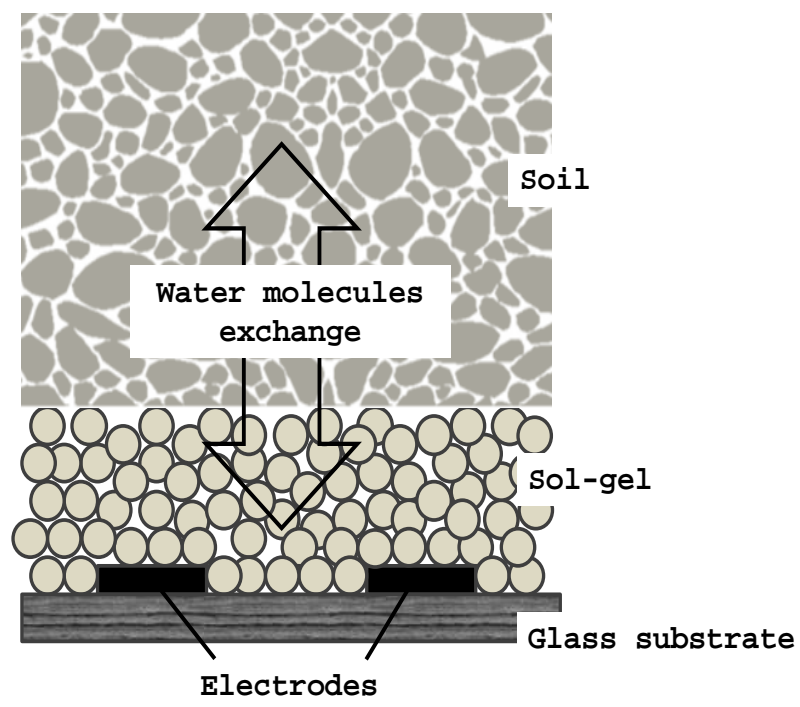

Figure 1. Scheme of the working principle of sol-gel sensors (without scale). 


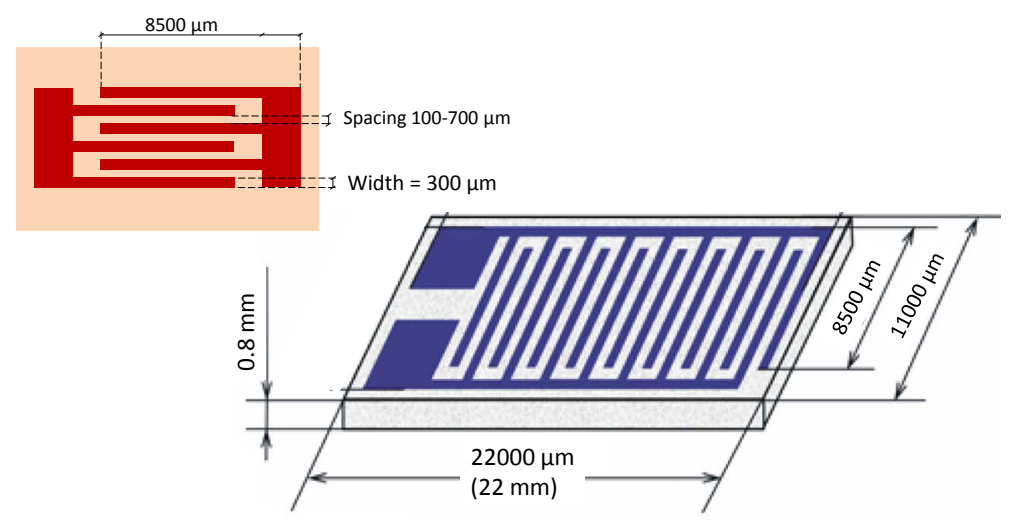

(a)

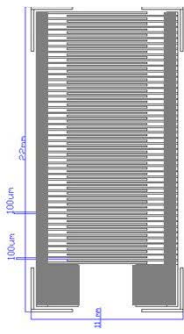

100

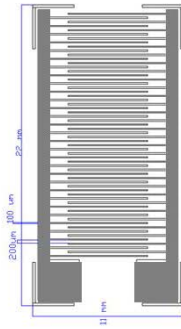

200

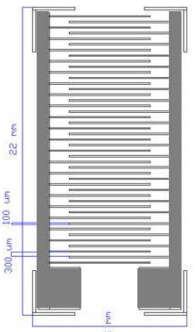

300

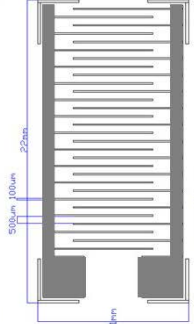

500

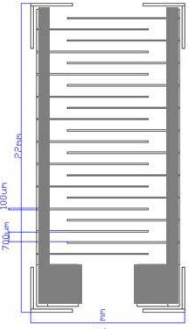

700

(b)

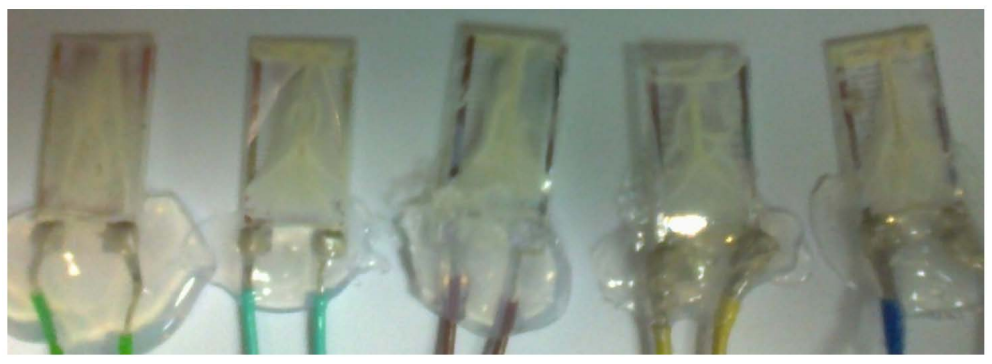

(c)

Figure 2. Sol-gel sensors: (a) Top view with the geometry of the interdigitated electrodes (length $8500 \mu \mathrm{m}$, width $100 \mu \mathrm{m}$ ) defined with spacing ranging from $100-700 \mu \mathrm{m}$; (b) Top view schematics and pictures of the sensors after sol-gel deposition and wiring; (c) Welded joins covered with silicone.

The active part of the sensor consists on a Cerium doped silica-titanium film deposited over the interdigitated electrodes using sol-gel technique described as follows. This porous material, which impedance varies with water presence, closes the electrical circuit.

\subsection{Sol-Gel}

The method for sol-gel fabrication was adapted from the work of Kozhukharov et al. [6], using a solution containing diammonium hexanitrocerate (named CAN) dissolved in isopropanol, polydimethylsiloxane trymetylsiloxy-terminated (PDTS) and titanium (IV) n-butoxide (TBOT). CAN has a catalytic effect as a Lewis acid in the hydrolysis of TBOT, and acts also as oxidant of the siloxane chains of 
PDTS. PDTS and TBOT are the silica and titanium sources, respectively. The composition of sol-gel is $60 \%$ titania and $40 \%$ silica.

Sol-gel deposition followed fixed steps. By order, the dissolution of CAN (full saturated solution) was performed in isopropanol previously heated to $80^{\circ} \mathrm{C}$. Then, the solution of CAN, PDTS and TBOT was prepared and was let reacting for $3 \mathrm{~h}$ under $85^{\circ} \mathrm{C}$. Ageing period was one week, under $5^{\circ} \mathrm{C}$. The deposition was done under $75^{\circ} \mathrm{C}$, in three dipping-drying steps, each taking 30 minutes. Finally, sintering was done under $400^{\circ} \mathrm{C}$ for 30 minutes. The substrate and Al/TiWN materials are fully stable at these temperatures. Sensor surface after sol-gel deposition is whitish and is shown in the photos in Figure 2(b). The thickness of the coating is less than $100 \mu \mathrm{m}$.

\section{Soil Characterization and Experimental Setup}

\subsection{Soil Used and Compaction Procedure}

The clay used is commercial white kaolin, with liquid limit of $52 \%$ and plastic index of $22 \%$, therefore the material classifies as highly plastic silt (MH) accordingly with the Unified Soil Classification System. The solid volumetric weight is $26.1 \mathrm{kN} / \mathrm{m}^{3}$. Several samples were prepared by manual compaction using a rod. The soil was compacted inside stiff steel rings $(7 \mathrm{~cm}$ diameter and $2 \mathrm{~cm}$ height $)$ and cut into 6 triangular pieces. Distilled water was used to reduce possible chemical interaction with sol-gel and dissolved salts. Final void ratio (relation between volume of voids and volume of solids) was e $=0.9$ and water content (relation between mass of water and mass of solids) was $\mathrm{w}=25 \%$. Soil suction correspondent to the water content at preparation is $0.8 \mathrm{MPa}$, which corresponds to a relative humidity of $99.4 \%$ at $21^{\circ} \mathrm{C}$ (laboratory temperature).

\subsection{Sensors Calibration Procedure}

The calibration consisted in gently push pieces of soil with known relative humidity against the sensor, and measure impedance once full contact was achieved. Current was measured applying constant DC voltage of $2.1 \mathrm{~V}$, therefore resistance was found using Ohm law. The measurements were done with the voltage/ current source Keithley Impedance meter, Model 2401. The readings were done after 2 minutes. This time was necessary for stabilization, and also to account with sensors capacitance (discussion latter).

The soil pieces used resulted from cutting in 6 triangular pieces the samples compacted inside the steel rings. The area of each piece was larger than the sensors area to allow full contact between the two porous materials. All soil pieces were dried in laboratory environment (constant temperature $21^{\circ} \mathrm{C} \pm 2^{\circ} \mathrm{C}$ and relative humidity $65 \% \pm 5 \%$ ). After drying, one piece was used as the driest case in real operating conditions in soils, while the remaining were partially wetted for the intended water contents. Wetting was done by controlled water addition followed by an equilibration time of 48 hours. The full saturated case was measured using a drop of water. 
The water content of each soil piece was defined so that the corresponding suction, after being converted into relative humidity (using Equation (1)), could cover a large suction interval. The value of the suction of the soil pieces was confirmed after being measured with a water potentiometer equipment, WP4C [13]. This equipment measures water potential, or suction, using the chilled-mirror dew point technique. Water potential, or total suction, ranges are from -0.5 to $-300 \mathrm{MPa}$. The sample is placed inside a sealed chamber that contains a mirror to which a beam of light is directed for detecting condensation. The temperature of the mirror is controlled by a thermoelectric (Peltier) cooler. A photoelectric cell detects the point at which condensation first appears on the mirror. In the chamber there is also an internal fan that circulates the air to reduce time to equilibrium. This time is also reduced because no thermal equilibrium is necessary since the sample temperature is controlled by an internal thermo-electrical module. This has the advantage of minimizing soil drying inside the chamber [14] [15].

Table 2 presents the values of suction and corresponding RH for each soil piece, computed with Equation (1). Three sensors were calibrated for each type of geometry. The same soil pieces were used for all sensors and the measurement consists on a drying followed by wetting sequence. Suction was measured in all pieces used during the process to account with possible drying during equilibrium time between measurements.

\subsection{Measurement of the Water Retention Curve}

The water retention curve, WRC, is the relationship between water content, $\mathrm{w}$, and total suction, $\Psi$. The information provided by this curve is fundamental to characterize the hydromechanical behaviour of unsaturated soils [1] [16] [17] and therefore its measurement is one of the most basic tests on unsaturated soils [15].

The other samples compacted inside the steel rings were used to incorporate sensors for the water retention curve measurements. The sensors were inserted in a compacted sample and wrapped gently to minimize soil disturbance (Figure 3). This procedure would cast in the sensor, preventing its detachment from the soil during drying. The sensors chosen (one for each spacing) were those with calibration curves closer to the average calibration curve.

As shown in Figure 3, the sensor, electrical wires and soil fit the cup sampler for WP4C measurements. The sensor and surrounding soil sample were dried by controlling their weight along time, followed by partial wetting by adding known

Table 2. Characteristics of the soil pieces used for sensors calibration.

\begin{tabular}{cccccccc}
\hline & 1 & 2 & 3 & 4 & 5 & 6 & drop of water \\
\hline w (\%) & 1.9 & 2.6 & 3.9 & 6.4 & 8.7 & 16.2 & -- \\
suction (MPa) & 49.12 & 19.74 & 10.38 & 7.92 & 2.45 & 1.90 & 0 \\
RH (\%) & 69.5 & 86.4 & 92.6 & 94.3 & 98.2 & 98.6 & 100 \\
\hline
\end{tabular}




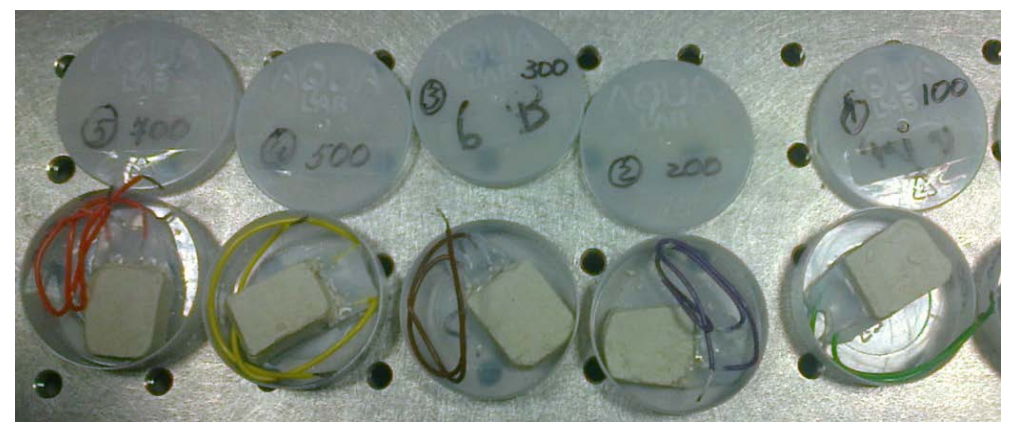

Figure 3. Sensors incorporated in soil specimens for suction measurement using WP4C.

small weights of water using a syringe. Equilibrium time after these changes was $24 \mathrm{~h}$. During this period the cups were covered (cover also in Figure 3) and the gap between the cover and the cup was sealed with isolating tape. Knowing that there is no loss of solids during the measurements, these changes in weight are due only to water mass lost or earned during the hydraulic path applied (respectively drying or wetting).

When in contact with soil the sensors adsorb water molecules from the soil pores. Suction was measured for each water content (obtained indirectly from weight changes) using WP4C. For simplification, suction will be considered positive, although water potential takes negative values for unsaturated soils. The impedance was measured using the sensors for the same points. The impedance readings were converted into $\mathrm{RH}$ using the sensors calibration curves, and then converted to suction using Kelvin law (Equation (1)). By this manner it was possible to compare the values provided by the sensors with those from WP4C.

\section{Characterization of the Sol-Gel}

\subsection{Homogeneity}

The non-homogeneity of the sol-gel layer is clearly visible in Figure 2, and is a consequence of the deposition process method (viscous flow). Figure 4 highlights three visible regions over the sensor where the sol-gel appears with different morphologies. The details of the microstructure are provided by the scanning electron microscope (SEM) pictures shown in Figures 4(b)-(d), where two different layers are seen, as well as the porous nature of sol-gel. It can be verified that during sol-gel formation the sol-gel solution wets the sensor surface with a very low contact angle, and there is no difference between Al/TiWN and glass surfaces. This can be seen in the photographs presented in Figure 5, showing drops of water and sol-gel in bare glass and covered with a thin aluminium film. While the angle changes for water $\left(59^{\circ} \mathrm{C}\right.$ for glass and $70^{\circ}$ for aluminium), for the sol-gel null angles were measured. This result indicates that sol-gel is highly hydrophilic in both substrates. Therefore, we are confident the wetting mechanism is homogeneous over the sensor area, and the heterogeneities could not be avoided even by dipping the sensors horizontally. As a consequence, the 


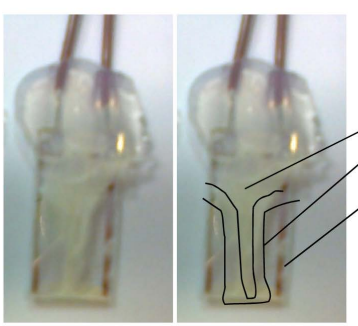

(a)

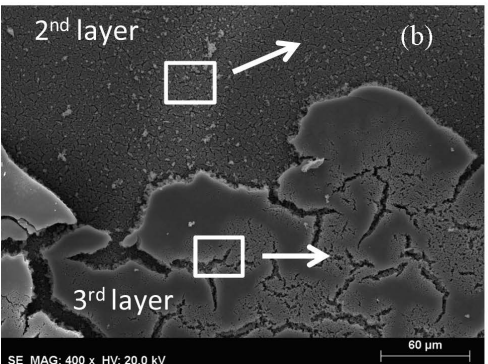

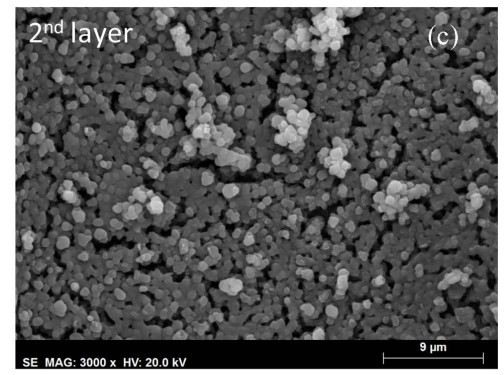

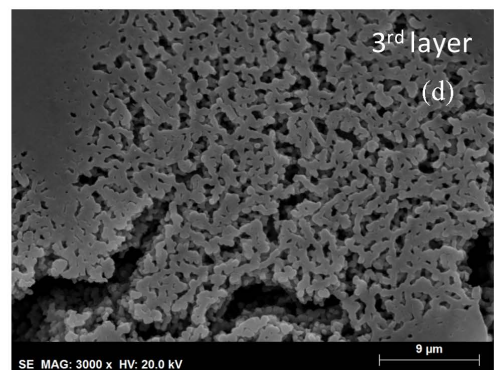

Figure 4. Sol-gel sensors: (a) Heterogeneity of sol-gel over the sensor, with 3 regions identified upon layer formation; (b) Regions with the different structured surfaces of the different layers; (c) Details on the pore sizes available in layer 2; (d) Details on the pore sizes available in layer 3.

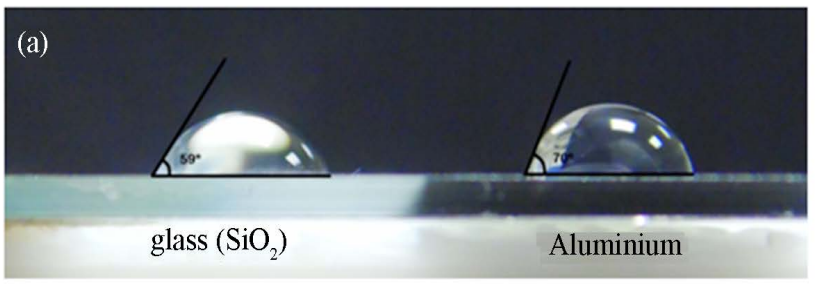

\section{(b)}

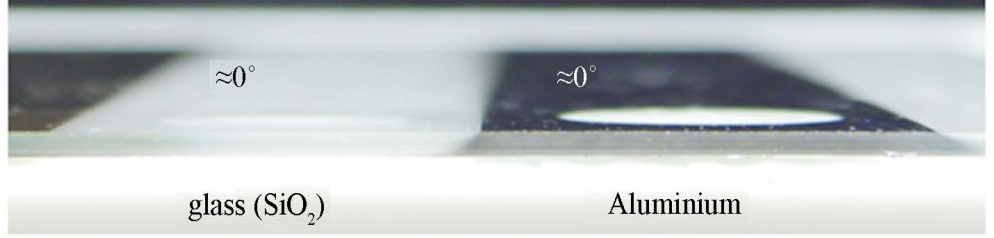

Figure 5. Comparison of the contact angles of water (a) and sol-gel (b) in corning glass and aluminium substrates.

aluminium electrodes spacing should have no impact on sol-gel morphology.

After sintering at $400^{\circ} \mathrm{C}$, the resulting sol-gel coating is a porous material, as observed in the scanning electron microscope (SEM) photograph presented in Figure 4. The pore structure is bimodal: macropores with average diameter of $100 \mathrm{~nm}$ and micropores (average pore diameter below $2 \mathrm{~nm}$ ) within spherical particles with almost uniform sizes (diameters around $1 \mu \mathrm{m}$ ). This porous structure, assessed by nitrogen adsorption-desorption isotherms (Figure 6(a)), is most suitable for humidity sensing. It is similar to the one recently obtained for sensors prepared using a microporous organic polymer based on 1,3,5-trihydroxybenzene [18]. 
Figure 4 shows that sol gel composition depends on the layer deposited. This motivated designing the sensors adopting a small spacing for the electrodes only in this area. This area is where sol-gel is more likely to have a triple layer. A deeper analysis of sol-gel deposition and homogeneity is out of the scope of this paper.

\subsection{Sol-Gel Compatibility with the Clay}

Figure 6 compares the adsorption-desorption isotherms for sol-gel (using nitrogen) with the intrusion-extrusion curves for compacted clay (with mercury). The first were performed with nitrogen at $77 \mathrm{~K}$ using Micrometrics ASAP 2010 V1.01 B and the second by mercury intrusion porosimetry (MIP) using AutoPore IV 9500 V1.07. The clay analysed was prepared as already described. It can be seen in Figure 6 that sol-gel pores are almost uniform due to the absence of hysteresis, while those for the clay studied are not. The different textures of the two materials are also highlighted in the SEM images presented in Figure 7.

SEM images allow identifying a dominant pore size of $40 \mathrm{~nm}$ for the compacted clay studied, a value within the ranges found for clayey soils (smallest pores ranging $20 \mathrm{~nm}$ to $200 \mathrm{~nm}$ ). This diameter is larger than that of sol-gel pores $(1 \mathrm{~nm})$, indicating that soil-gel will be more sensitive to relative humidity

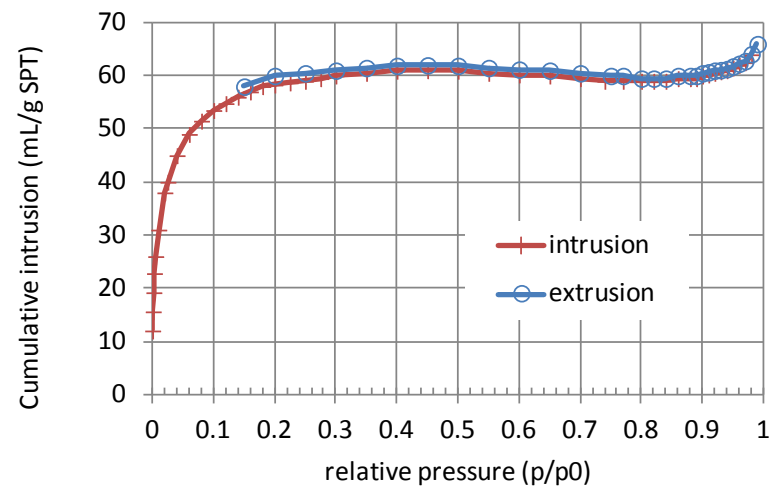

(a)

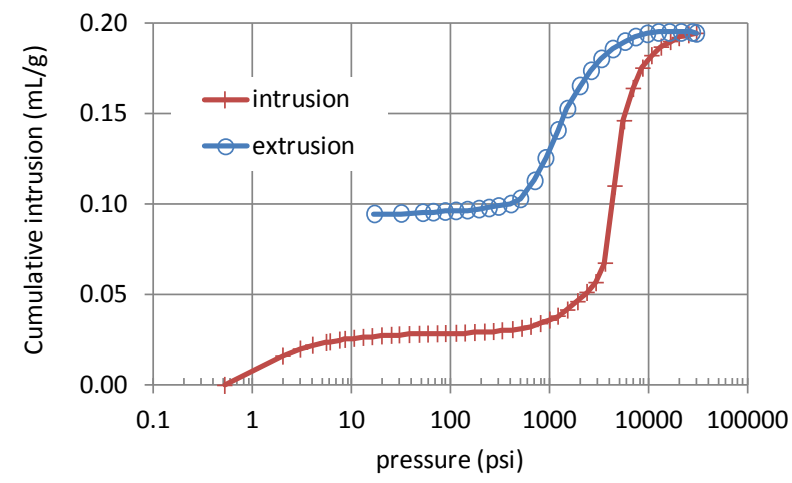

(b)

Figure 6. (a) Adsorption-desorption isotherms for sol-gel (nitrogen); (b) Intrusion-extrusion curves for compacted clay (mercury). 


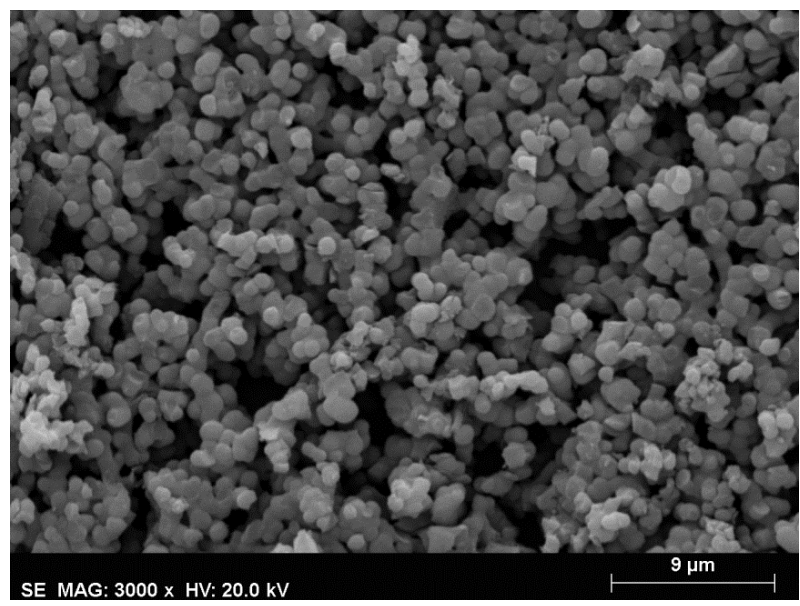

(a)

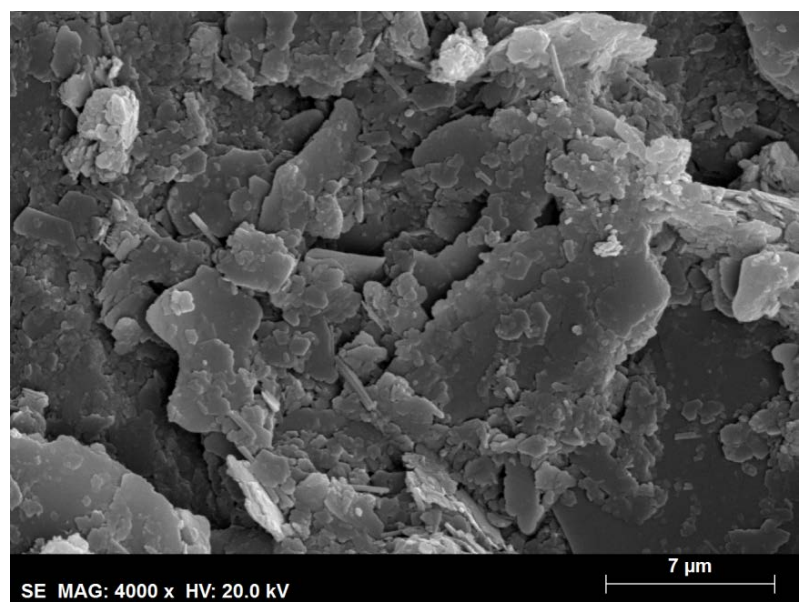

(b)

Figure 7. SEM photographs of (a) Sol-gel coating; (b) Compacted clay studied.

than the clay. Sol-gel pores are smaller than the pores of the clayey soil investigated and therefore the continuity of the gas phase in the two porous medium can be ensured. For this reason we can consider sol-gel sensors adequate for the clayey soils studied.

\subsection{Range and Sensitivity}

The sol-gel porous coating is responsible for the required sensor sensitivity to water in gas phase. Sensors sensitivity is the slope of the calibration curves relating impedance with RH. Accordingly with Laplace equation, the sensitivity to $\mathrm{RH}$ depends on the diameter of the sol-gel pores and is associated to capillarity effects as described by Laplace equation,

$$
r_{k}=\frac{2 \gamma M}{\rho R T \ln \left(\frac{P}{P_{s}}\right)}
$$

where $r_{k}$ is the Kelvin radius of the cylindrical open pores (open at both ends), $\gamma$ 
is the surface tension of water $\left(72.75 \times 10^{-3} \mathrm{~N} / \mathrm{m}\right.$ at $\left.20^{\circ} \mathrm{C}\right), M$ is the molecular mass of water $(18.016 \mathrm{~kg} / \mathrm{kmol}), \rho$ is the density of pure water and $R$ is the gas constant, both already presented and $T$ is the absolute temperature. $P$ is the water vapour pressure and $P_{s}$ is the water vapour pressure at saturation (the ratio $P / P_{s}$ is the relative humidity, $\left.\mathrm{RH}\right)$.

In accordance with the size of the sol-gel pores $(2 \mathrm{~nm}$ and $200 \mathrm{~nm}$-approx. maximum value), using Equation (2), the processes adopted for sol-gel preparation have resulted in sensors operating in values of air relative humidity, $\mathrm{RH}$, between $1 \%$ and $99 \%$. This range is generally found in the literature, and relationship between impedance and RH (in logarithmic scale) is linear. Further details on sol-gel sensors working principle are explained by Rittersma [3] and Kozhukharov et al. [4] [5].

It is expected that sol-gel maximum operation range and sensitivity will be affected by the contact with the clay (in terms of measurement range, sensitivity and hysteresis) because the compacted clay is also a porous material, in which pores diameter depend of the minerals present and the compaction process adopted. These differences allow anticipate that the calibration of the RH sensors for this particular application must be done against the soil and not in humid air (usually, for soils the humidity is controlled by salt solutions [15]). It has the advantage of accounting with possible sol-gel pore clogging with clay particles and consequent effect in sensors' speed and sensitivity.

\section{Sensors Calibration}

\subsection{Response Time and Capacitance}

In each measurement, DC voltage was turned on only the time necessary for current to become stable (about two minutes for each reading) in each point measurement. The capacitive effect reflects in this initial two minutes, but voltage changes are inferior to $1 \%$ of the average reading at the end of this short period of time. Figure 8 presents one curve measured for one of the $200 \mu \mathrm{m}$ spacing sensors when measuring one soil piece with $\mathrm{RH}=92.6 \%$ as an example of the sensors behaviour and to justify the choice of using the reading after $2 \mathrm{mi}$ nutes. Data acquisition was done manually.

The soil was in contact with the sol-gel sensor for at least two minutes before turning on the power, to ensure enough time for equilibrium. Therefore, in total, each measurement took around 5 minutes.

\subsection{Calibration Curves}

The soil pieces previously described were used for the calibration of the sensors. As said, the use of soil pieces is considered to be more suitable than using salt solutions to calibrate such sensors because this mimics the sensors operating environment.

The average values of the readings using the soil pieces are presented in Figure 9. A bilinear relation could be found, one branch for the high $\mathrm{RH}$ range and 


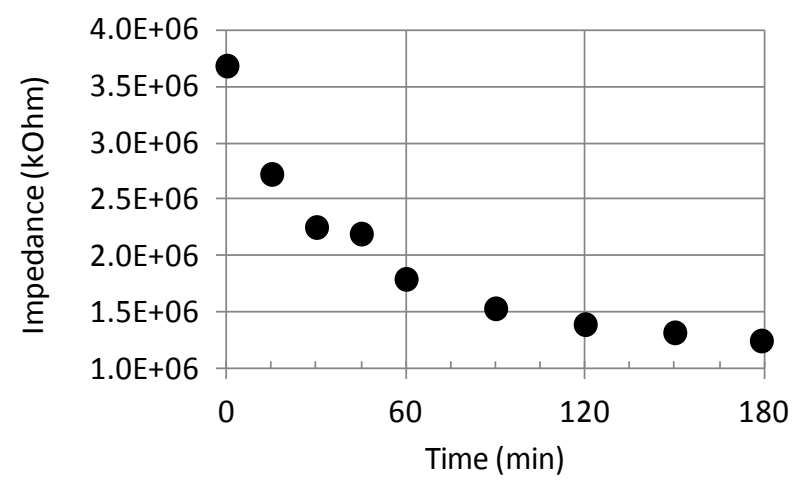

Figure 8. Impedance evolution along time for a one of the 200 $\mu \mathrm{m}$ spacing sensors measuring a piece of soil with $\mathrm{RH}=92.6 \%$. The values are stable at the end of 2 minutes.

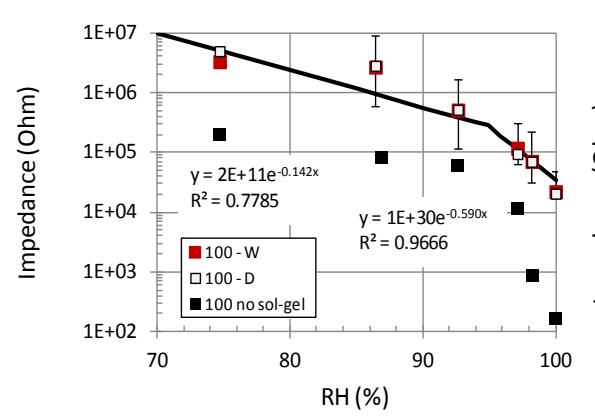

(a)

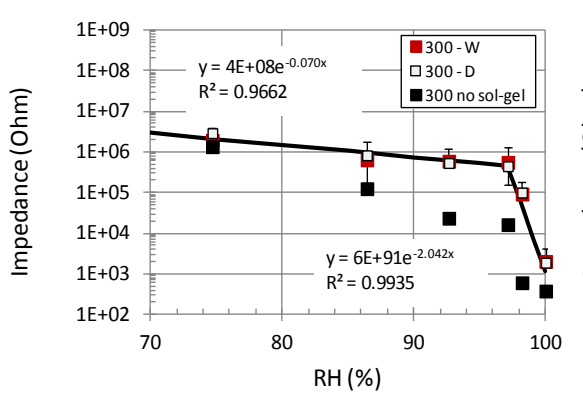

(c)

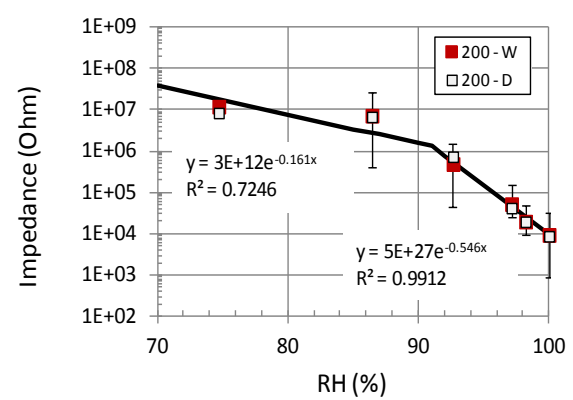

(b)

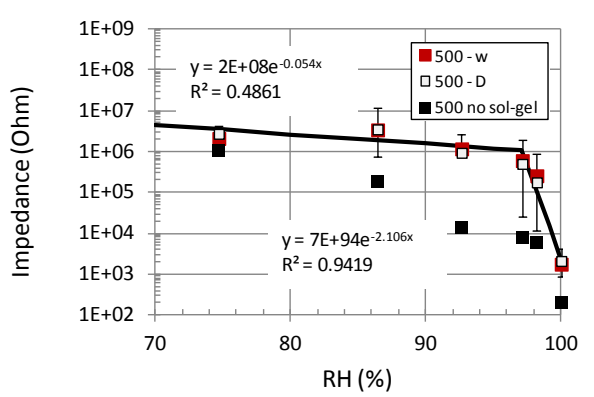

(d)

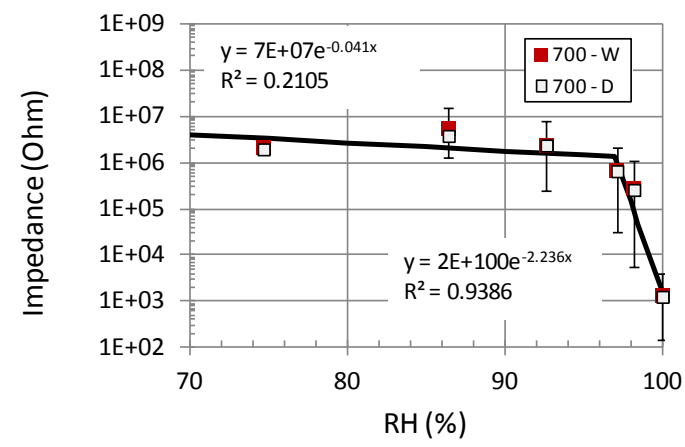

(e)

Figure 9. Calibration curves of the sensors against soil pieces (drying-wetting paths): (a) $100 \mu \mathrm{m}$; (b) $200 \mu \mathrm{m}$; (c) $300 \mu \mathrm{m}$; (d) $500 \mu \mathrm{m}$; (e) $700 \mu \mathrm{m}$. 
the other for the low. Sensitiveness decreases for the lowest RH. The values of $\mathrm{RH}$ at the transition (and corresponding suction computed with Equation (1)) are in Table 3.

The error bars were computed considering the maximum and minimum values found. The best fitting exponential trends found are also in the figure and in Table 3. The error is acceptable mainly for the high $\mathrm{RH}$ range. For the low $\mathrm{RH}$, error may be explained by small number of measurements in this range, an eventually by less contact between the sensors and soil. This is mainly due to the increment of soil stiffness caused by drying.

\subsection{Hysteresis}

It can be seen in Figure 9 that the points measured along the wetting and drying paths are fitted well by the same relationship, therefore no significant hysteresis was found. This result was expected for sol-gel sensors, as reported in the literature ([3] [5] [6] [7] [8] [18], among others), and is consistent with the uniform pore size distribution of the sol-gel (Figure 6(a)). It is admitted that sol-gel porous size distribution is not affected by eventual clay particles filling its pores.

\subsection{Electrodes Spacing}

The comparison of all fitting curves is presented in Figure 10. Here the impact of the electrode spacing is highlighted, with the larger differences observed for the sensors with the smaller electrode spacing (100 and $200 \mu \mathrm{m}$ ), when compared with the others. Several trends can be then identified:

- For the low RH, sensitivity decreases with increasing spacing. The highest sensitivity was found for $200 \mu \mathrm{m}$, similar to that of $100 \mu \mathrm{m}$. The values measured are similar for 300, 500 and $700 \mu \mathrm{m}$ and are very small.

- For the high RH, sensitivity increases with increasing spacing between electrodes. The largest increment is observed between 200 and $300 \mu \mathrm{m}$. All sensors appear to be adequate to perform readings in this range.

With decreasing spacing the resolution increases (there are more electrodes in the same contact area between soil and sol-gel) and therefore also increases the probability to detect less amounts of water. For this reason 100 or $200 \mu \mathrm{m}$ are

Table 3. Calibration curves for the sensors considering average values.

\begin{tabular}{cccc}
\hline $\begin{array}{c}\text { SENSOR SPACING } \\
(\mu \mathrm{m})\end{array}$ & Low RH & High RH & $\begin{array}{c}\text { RH at the transition } \\
\text { (suction) }\end{array}$ \\
\hline 100 & $\mathrm{y}=2 \mathrm{E}+11 \mathrm{e}^{-0.142 \mathrm{x}}$ & $\mathrm{y}=1 \mathrm{E}+30 \mathrm{e}^{-0.590 \mathrm{x}}$ & $94.9 \%(7.09 \mathrm{MPa})$ \\
& $\mathrm{R}^{2}=0.7785$ & $\mathrm{R}^{2}=0.9666$ & \\
$\mathrm{y}=3 \mathrm{E}+12 \mathrm{e}^{-0.161 \mathrm{x}}$ & $\mathrm{y}=5 \mathrm{E}+27 \mathrm{e}^{-0.546 \mathrm{x}}$ & $91.0 \%(12.78 \mathrm{MPa})$ \\
200 & $\mathrm{R}^{2}=0.7246$ & $\mathrm{R}^{2}=0.9912$ & \\
& $\mathrm{y}=4 \mathrm{E}+08 \mathrm{e}^{-0.070 \mathrm{x}}$ & $\mathrm{y}=6 \mathrm{E}+91 \mathrm{e}^{-2.042 \mathrm{x}}$ & $97.1 \%(3.97 \mathrm{MPa})$ \\
300 & $\mathrm{R}^{2}=0.9662$ & $\mathrm{R}^{2}=0.9935$ & \\
& $\mathrm{y}=2 \mathrm{E}+08 \mathrm{e}^{-0.054 \mathrm{x}}$ & $\mathrm{y}=7 \mathrm{E}+94 \mathrm{e}^{-2.106 \mathrm{x}}$ & $97.1 \%(3.97 \mathrm{MPa})$ \\
500 & $\mathrm{R}^{2}=0.4861$ & $\mathrm{R}^{2}=0.9419$ & \\
& $\mathrm{y}=7 \mathrm{E}+07 \mathrm{e}^{-0.041 \mathrm{x}}$ & $\mathrm{y}=2 \mathrm{E}+100 \mathrm{e}^{-2.236 \mathrm{x}}$ & $96.7 \%(4.53 \mathrm{MPa})$ \\
& $\mathrm{R}^{2}=0.2105$ & $\mathrm{R}^{2}=0.9386$ & \\
\hline
\end{tabular}


better for measurements in the low $\mathrm{RH}$ ranges, or for low suctions. For the high $\mathrm{RH}$, in the presence of large amounts of water, a lower resolution appears to be better, maybe because saturation detected in some areas could be masking the overall signal.

\subsection{Homogeneity of Sol-Gel}

The effect of the sol-gel coating was investigated for sensors with 100, 300 and $500 \mu \mathrm{m}$ electrodes spacing. In this complementary study one sensor without solgel coating was calibrated directly against clay samples (calibration curves in Table 4). The comparisons of the readings are also presented in Figure 9 and Figure 10 and in Table 3 and Table 4. In all cases impedance decreases for the sensors without sol-gel. For the low RH sensitivity is larger without sol-gel (Figure 10). For the high $\mathrm{RH}$, except for $100 \mu \mathrm{m}$, there is an overall decrease in sensitivity also without sol-gel. This result confirms that sol-gel affects sensor performance and enhances the sensor's sensitivity in the high $\mathrm{RH}$ range.

The comparison between the curves with and without sol-gel shown in Figure 9 and in Table 3 and Table 4 indicates that sol-gel heterogeneity may have in-
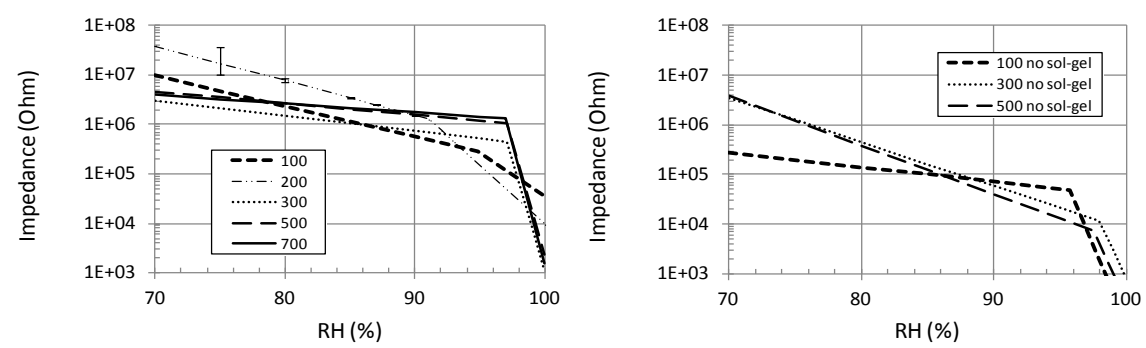

(a)
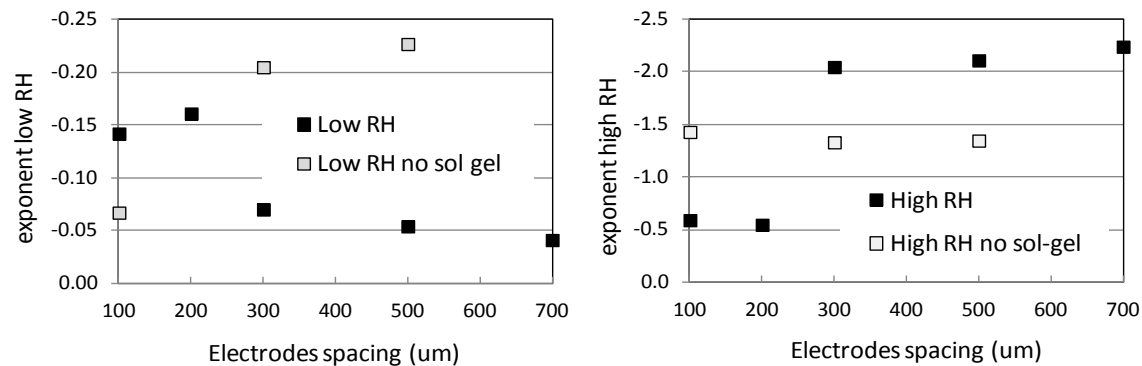

(b)

Figure 10. Comparison of the calibration curves: (a) Overall view; (b) Slopes.

Table 4. Calibration curves for the sensors without sol-gel.

\begin{tabular}{cccc}
\hline $\begin{array}{c}\text { SENSOR SPACING } \\
(\mu \mathrm{m})\end{array}$ & Low RH & High RH & $\begin{array}{c}\text { RH at the transition } \\
(\text { suction })\end{array}$ \\
\hline 100 & $\mathrm{y}=3 \mathrm{E}+07 \mathrm{e}^{-0.067 \mathrm{x}}$ & $\mathrm{y}=1 \mathrm{E}+64 \mathrm{e}^{-1.427 \mathrm{x}}$ & $95.7 \%(5.97 \mathrm{MPa})$ \\
& $\mathrm{R}^{2}=0.9930$ & $\mathrm{R}^{2}=0.9382$ & \\
300 & $\mathrm{y}=6 \mathrm{E}+12 \mathrm{e}^{-0.205 \mathrm{x}}$ & $\mathrm{y}=4 \mathrm{E}+60 \mathrm{e}^{-1.329 \mathrm{x}}$ & $98.0 \%(2.74 \mathrm{MPa})$ \\
& $\mathrm{R}^{2}=0.9863$ & $\mathrm{R}^{2}=0.9189$ & \\
500 & $\mathrm{y}=3 \mathrm{E}+13 \mathrm{e}^{-0.227 \mathrm{x}}$ & $\mathrm{y}=7 \mathrm{E}+60 \mathrm{e}^{-1.345 \mathrm{x}}$ & $97.6 \%(3.29 \mathrm{MPa})$ \\
& $\mathrm{R}^{2}=0.9401$ & $\mathrm{R}^{2}=0.8987$ & \\
\hline
\end{tabular}


fluence in the error because the sizes of the error bars are larger in the transition between the high and low $\mathrm{RH}$. This is the region where larger discrepancies were found between the curves with and without sol-gel.

The homogeneity of sol-gel can also be affecting the results. It is more likely this coat to be homogeneous in small areas and therefore different signals will be detected for high resolutions. For the final signal the weight of each small area depends on the total number of areas and decreases with spacing. Therefore is expected that the heterogeneity will affect less the sensors with higher resolution, or smaller spacing between electrodes. Data collected does not allow a better analysis of this topic.

\section{Measurement of the Soil Water Retention Curve}

\subsection{Impedance Measurements during the Drying Wetting Cycles}

The curves relating sensors impedance with soil water content, suction and relative humidity are presented in Figure 11 for drying followed by wetting. Relative humidity was computed with Equation (1), using the values of suction measured with WP4C. These curves should be similar to the calibration curves because the procedures followed are similar.

For comparison purposes, in the plot impedance vs. relative humidity in Figure 11 the calibration curve of the sensors used (Table 5) is also presented. It can be seen that the incorporation of the sensor in the clay decreases impedance. This may be the effect of the electrical conductivity of the surrounding clay, some osmotic effects or the effect of some sol-gel removal during the installation.

Hysteresis can be seen in all cases, which is more evident for the largest water contents, or lowest suctions. This results from the water retention properties of the soil surrounding the sensor and not from the sensor itself. Indeed, soil has a known hysteretic behaviour, observed also in the mercury intrusion porosimetry

Table 5. Calibration curves for the sensors used to measure the water retention curve.

\begin{tabular}{cccc}
$\begin{array}{c}\text { SENSOR SPACING } \\
(\mu \mathrm{m})\end{array}$ & Low RH & High RH & $\begin{array}{c}\text { RH at the transition } \\
(\text { suction })\end{array}$ \\
\hline 100 & $\mathrm{y}=2 \mathrm{E}+11 \mathrm{e}^{-0.142 \mathrm{x}}$ & $\mathrm{y}=1 \mathrm{E}+30 \mathrm{e}^{-0.590 \mathrm{x}}$ & $94.9 \%(7.09 \mathrm{MPa})$ \\
100 corrected & $\mathrm{y}=12 \mathrm{E}+03 \mathrm{e}^{-0.046 \mathrm{x}}$ & $\mathrm{y}=2 \mathrm{E}+65 \mathrm{e}^{-1.443 \mathrm{x}}$ & $94.9 \%(5.59 \mathrm{MPa})$ \\
200 & $\mathrm{y}=6 \mathrm{E}+14 \mathrm{e}^{-0.247 \mathrm{x}}$ & $\mathrm{y}=6 \mathrm{E}+42 \mathrm{e}^{-0.906 \mathrm{x}}$ & $97.8 \%(3.01 \mathrm{MPa})$ \\
200 corrected & $\mathrm{y}=4 \mathrm{E}+03 \mathrm{e}^{-0.020 \mathrm{x}}$ & $\mathrm{y}=2 \mathrm{E}+59 \mathrm{e}^{-1.296 \mathrm{x}}$ & $95.1 \%(6.81 \mathrm{MPa})$ \\
300 & $\mathrm{y}=4 \mathrm{E}+08 \mathrm{e}^{-0.070 \mathrm{x}}$ & $\mathrm{y}=6 \mathrm{E}+91 \mathrm{e}^{-2.042 \mathrm{x}}$ & $97.1 \%(3.97 \mathrm{MPa})$ \\
300 corrected & $\mathrm{y}=16 \mathrm{E}+03 \mathrm{e}^{-0.047 \mathrm{x}}$ & $\mathrm{y}=2 \mathrm{E}+41 \mathrm{e}^{-0.866 \mathrm{x}}$ & $95.9 \%(5.68 \mathrm{MPa})$ \\
500 & $\mathrm{y}=2 \mathrm{E}+08 \mathrm{e}^{-0.054 \mathrm{x}}$ & $\mathrm{y}=7 \mathrm{E}+94 \mathrm{e}^{-2.106 \mathrm{x}}$ & $97.1 \%(3.97 \mathrm{MPa})$ \\
500 corrected & $\mathrm{y}=3 \mathrm{E}+03 \mathrm{e}^{-0.014 \mathrm{x}}$ & $\mathrm{y}=5 \mathrm{E}+56 \mathrm{e}^{-1.210 \mathrm{x}}$ & $96.3 \%(5.16 \mathrm{MPa})$ \\
700 & $\mathrm{y}=5 \mathrm{E}+13 \mathrm{e}^{-0.177 \mathrm{x}}$ & $\mathrm{y}=2 \mathrm{E}+100 \mathrm{e}^{-2.236 \mathrm{x}}$ & $96.8 \%(4.41 \mathrm{MPa})$ \\
700 corrected & $\mathrm{y}=3 \mathrm{E}+013 \mathrm{e}^{-0.020 \mathrm{x}}$ & $\mathrm{y}=5 \mathrm{E}+59 \mathrm{e}^{-1.281 \mathrm{x}}$ & $91.1 \%(3.97 \mathrm{MPa})$ \\
\hline
\end{tabular}



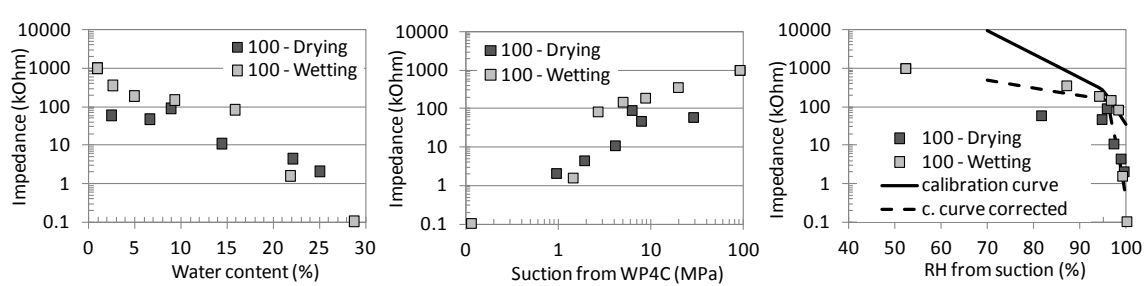

(a)
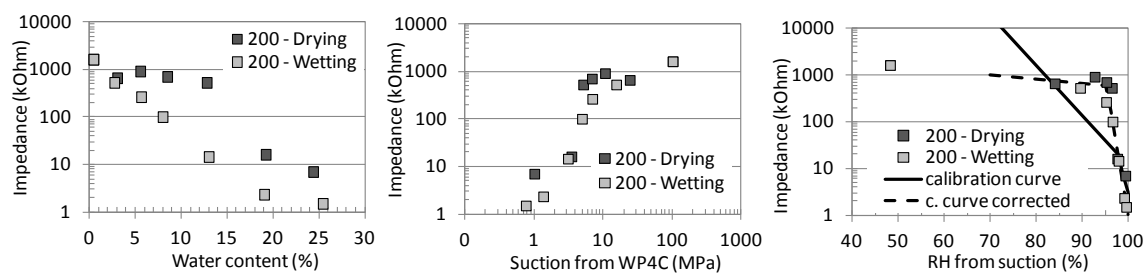

(b)
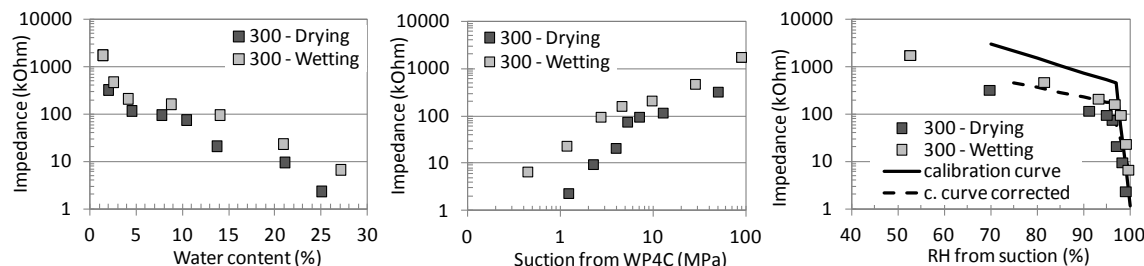

(c)
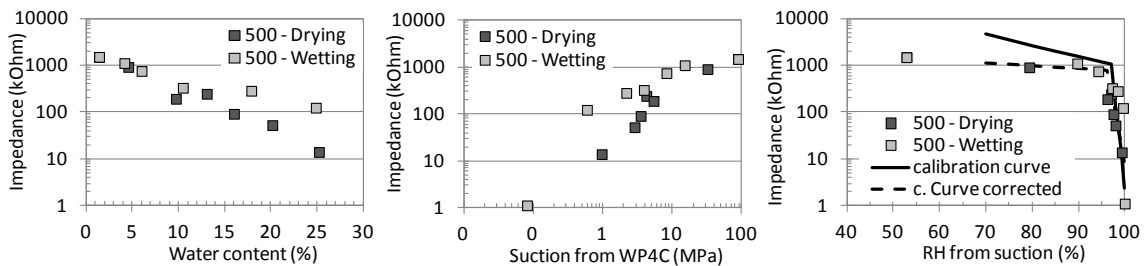

(d)
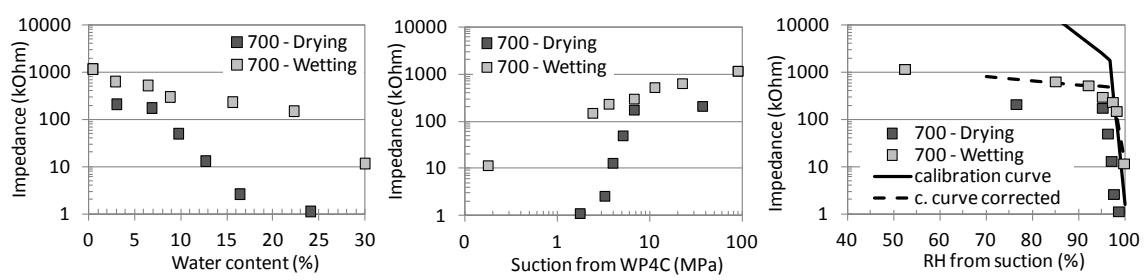

(e)

Figure 11. Impedance versus water content, suction and relative humidity in drying wetting paths for electrodes spacing: (a) $100 \mu \mathrm{m}$; (b) $200 \mu \mathrm{m}$; (c) $300 \mu \mathrm{m}$; (d) $500 \mu \mathrm{m}$; (e) 700 $\mu \mathrm{m}$.

tests previously presented in Figure 6(b). Hysteresis is be explained by different amounts of water in the gas or liquid phases during wetting or drying paths under constant temperature (isotherms), due to pore size distribution and geometry [1] [16] [17] [19].

\subsection{Water Retention Curve}

The water retention curve of the soil can be fitted from the points measured with 
WP4C equipment using Equation (3) proposed by Van Genuchten [20],

$$
S_{r}=\frac{G_{s}}{e} w=\left[1+\left(\frac{s}{P}\right)^{\frac{\lambda}{1-\lambda}}\right]^{-\lambda}
$$

where $S_{r}$ is the degree of saturation (volume of water in the volume of voids), Gs is the solid weight density ( $G s=2.61$ for the clay studied), $e$ is voids ratio (volume of voids above the volume of solids, $e=0.9$, assumed constant), $w$ is water content, $s$ is suction, $P$ is the suction corresponding to the air entry value (when the gas phase becomes continuous in the pores) and $\lambda$ is a fitting parameter. For the compacted clay studied the parameters found are $\mathrm{P}=0.55 \mathrm{MPa}$ and $\lambda=$ 0.040 for the drying branch, and $\mathrm{P}=0.15 \mathrm{MPa}$ and $\lambda=0.035$ for the wetting branch. The points and curves are presented in Figure 12(a), where soil hysteresis is evident because the two curves do not overlap.

Figure 12(b) presents the same curves, but with the points found using suction computed from impedance. Suction measured by the sensors should be the same as that from WP4C. The results are close for sensors with electrodes spacing $300 \mu \mathrm{m}$, followed by $500 \mu \mathrm{m}$, however with some problems in the wetting branch. For 100 and $700 \mu \mathrm{m}$ spacing the curves overlap. This is not correct so these sensors must be excluded.

\subsection{Correction of the Calibration Curve}

For 100 and $200 \mu \mathrm{m}$ spacing the sensors do not have good sensitiveness for the low suctions (high relative humidity). This was observed also during their calibration. For the high suctions (low relative humidity) all sensors have problems because they underestimate suction. This is consistent with the fact that impedance measured after sensors incorporation in soil was lower than that of the calibration curve, therefore this is a calibration problem. The deviations may be explained by the time necessary for equilibrium between the water in the soil and in sol-gel (analysis out of the scope of this paper). The calibration was done in a fast way (around 5 minutes) when compared with WP4C measurements (about 24 hours).

In order to overcome this problem the calibration curves were corrected for the low suction ranges considering WP4 readings. The equations, presented in Table 5 (identified with the word "corrected"), were used to define the new water retention curve using suction computed from impedance. The calibration curves after this correction were included in Figure 13 (named "curve cor rected") as well.

The water retention curve defined after the correction is presented in Figure 13. In general, it can be seen improvements both in the low and the high suction ranges. The best sensor before the correction was that with $300 \mu \mathrm{m}$ electrodes spacing, however after the correction their ability to detect soil hysteresis was lost. The comparison is presented in Figure 13. This is because sensitivity was reduced in general, which was good for the high RH but not good for the 


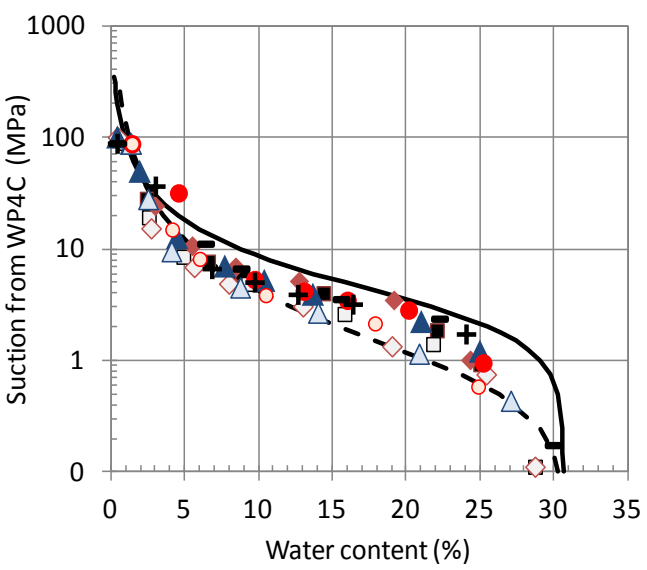

- 100 -Drying

- 100 -Wetting

- 200 -Drying

$\diamond 200$-Wetting

A 300 -Drying

$\triangle 300$-Wetting

- 500 -Drying

- 500 -Wetting

+ 700 -Drying

- 700 - Wetting

- Soil - Drying

- - Soil- Wetting

(a)

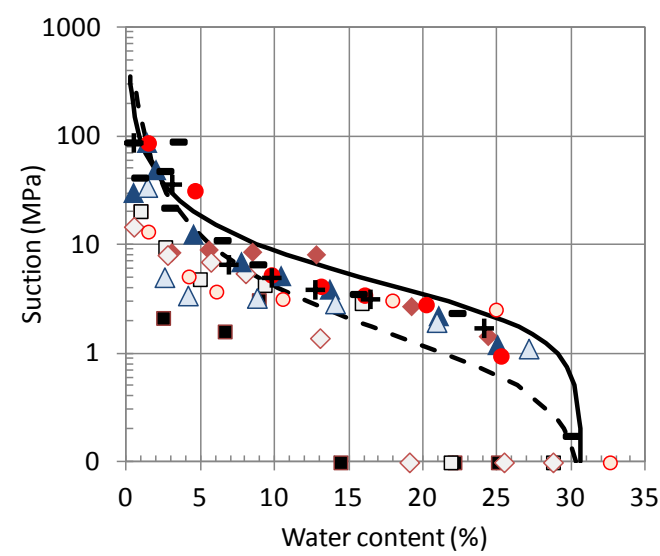

- 100 - Drying

100 -Wetting

- 200 -Drying

$\curvearrowright 200$-Wetting

- 300 -Drying

$\triangle 300$-Wetting

- 500 - Drying

- 500 -Wetting

+ 700 -Drying

- 700 - Wetting

-Drying WP4C

- - Wetting WP4C

(b)

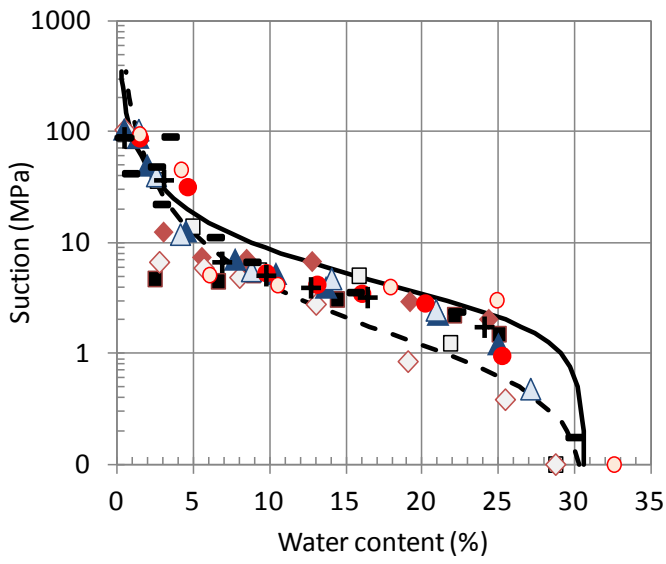

- 100 - Drying

ㅁ 100 -Wetting

- 200 -Drying

$\diamond 200$-Wetting

\300-Drying

$\triangle 300$ - Wetting

- 500 - Drying

○ 500 - Wetting

+700 - Drying

- 700 - Wetting

- Drying WP4C

- - Wetting WP4C

(c)

Figure 12. Water retention curves measured: (a) With WP4C; (b) With the sensors considering their calibration curves; (c) With the sensors after correcting the calibration curves.

low ones.

Figure 13(b) presents the results found for the sensor with $200 \mu \mathrm{m}$ electrodes spacing. Before the correction the sensors had problems in the high $\mathrm{RH}$, as pre- 

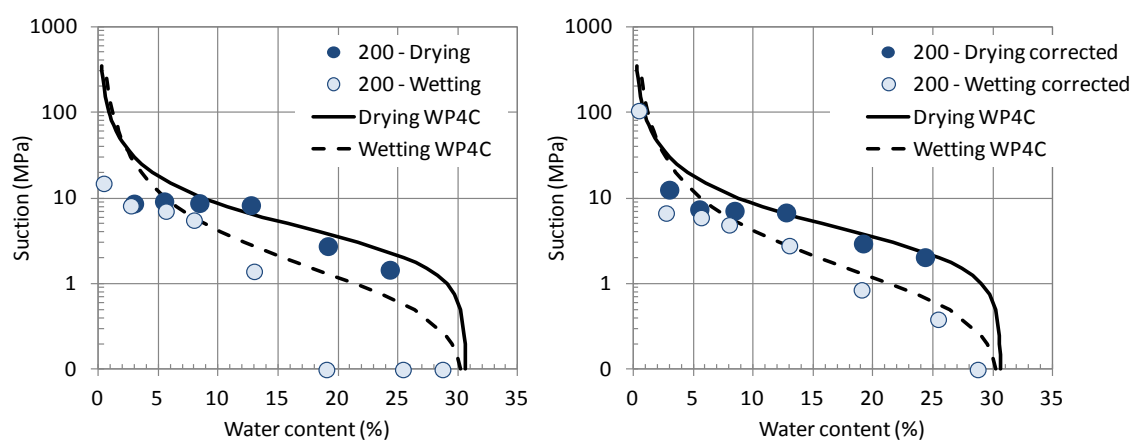

(a)
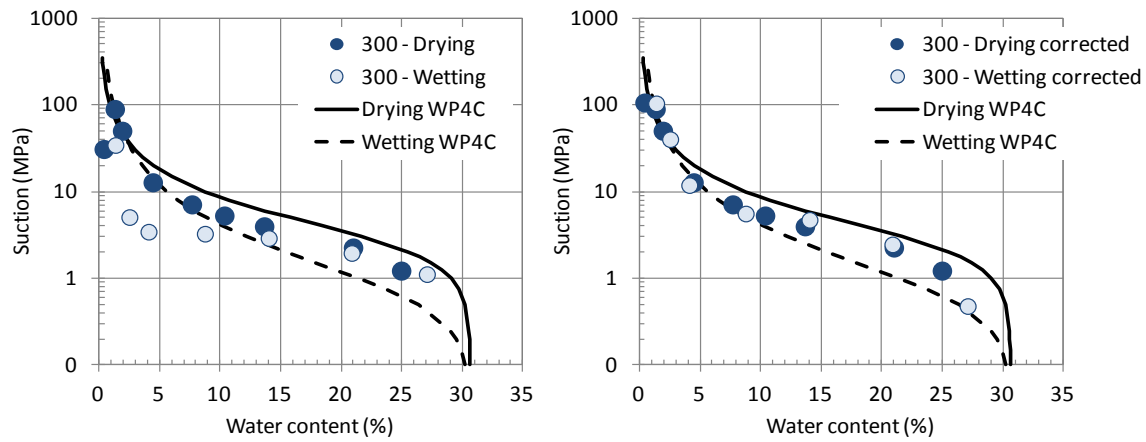

(b)

Figure 13. Improvements achieved with the correction for electrodes spacing: (a) $200 \mu \mathrm{m}$; (b) $300 \mu \mathrm{m}$.

viously discussed, but the results after correction fit well the WRC of the clayey soil. Therefore, among the sensors studied, this can be considered the best sensor for soil suction measurements.

To conclude, the calibration must be done using WP4C equipment instead of pieces of soil, to ensure perfect contact and guarantee equilibrium between the two porous materials.

\section{Conclusions}

The water retention curve of compacted kaolin was measured and compared with the curve found using water dew point potentiometer WP4C, validating the use of the sol-gel sensors in clayey soils. The correction of the calibration curve was necessary to consider vapour equilibrium between sol-gel and the soil, as well as the influence of the electrical conductivity of the soil surrounding the sensors and eventual sol-gel clogging with clay particles or sol-gel removal during sensors installation.

These sensors provided acceptable measurements for suction ranges between $1 \mathrm{MPa}$ and $10 \mathrm{MPa}$ after correction, being $200 \mu \mathrm{m}$ the best electrodes spacing. When comparing with other sensors operating inside soil specimens in standard laboratorial tests (see Table 1), these sol-gel sensors extend the operation range available with the alternative technologies: while conventional tensiometers measure suction ranges from 0 to $1.8 \mathrm{MPa}$, our sensors demonstrate good results be- 
tween 1 to $10 \mathrm{MPa}$ (and higher). Such operating range is particularly important for clayey soils because their transition between saturated and non-saturated states can be above $2 \mathrm{MPa}$ due to the small size of the soil pores.

Here, negligible chemical interaction between the soil and sol-gel is assumed, because distilled water was used in the tests. However, when existing, these effects would be independent of the electrode geometry, therefore the comparative results between sensors performances would remain valid in other environments.

The optimization of sol-gel deposition would highly improve the reproducibility and data dispersion. Nevertheless, the sensors developed had accomplished the specifications required. Therefore, this study demonstrates the high scientific potential of sol-gel relative humidity sensors as a novel tool for testing and characterizing the hydro-mechanical behaviour of unsaturated soils.

\section{Acknowledgements}

The authors thank Portuguese Foundation for Science and Technology, FCT, for the financial support provided to the research project EXPL/ECM-GEO/0109/ 2013. INESC-MN acknowledges FCT funding through the IN Associated Laboratory. G. Sarapajevaite acknowledges ERASMUS+ program through Kaunas University, Lithuania, during her internship. Acknowledge is also due to Miss Carla Piteira for her help measuring the contact angles.

\section{References}

[1] Fredlund, D.G. and Rahardjo, H. (1993) Soil Mechanics for Unsaturated Soils. John Wiley and Sons, New York. https://doi.org/10.1002/9780470172759

[2] Traversa, E. (1995) Ceramic Sensors for Humidity Detection: The State-of-the-Art and Future Developments. Sensors and Actuators B, 23, 135-156.

[3] Rittersma, Z.M. (2002) Recent Achievements in Miniaturizd Humidity Sensors-A Review of Transducer Techniques. Sensor and Actuators A, 96, 196-210.

[4] Albrecht, B., Benson, C. and Beuermann, S. (2003) Polymer Capacitance Sensors for Measuring Soil Gas Humidity in Drier Soils. Geotechnical Testing Journal, 26, 1-9.

[5] Kozhukharov, S., Nenova, Z., Nenov, T., Nedev, N. and Machkova, M. (2013) Elucidation of the Contribution of Modified Titania Films over the Performance of Thin Film Humidity Sensors. Journal of Chemical Technology and Metallurgy, 48, 142-146.

[6] Kozhukharov, S., Nenova, Z., Nenov, T., Nedev, N. and Machkova, M. (2015) Humidity Sensing Elements Based on Cerium Doped Titania-Silica Thin Films Prepared via a Sol-Gel Method. Sensors and Actuators B, 210, 676-684.

[7] Sukhyy, K.M., Gomza, Y.P., Belyanovskaya, E.A., Klepko, V.V., Shilova, O.A. and Sukhyy, M.P. (2015) Resistive Humidity Sensors Based on Proton-Conducting Organic-Inorganic Silicophosphates Doped by Polyionenes. Journal of Sol-Gel Science and Technology, 74, 472-481. https://doi.org/10.1007/s10971-015-3622-7

[8] Yuan, Q., Li, N., Geng, W., Chi, Y., Tu, J., Li, X. and Shao, C. (2011) Humidity Sensing Properties of Mesoporous Iron Oxide/Silica Composite Prepared via Hydrothermal Process. Sensors and Actuators B, 160, 334-340.

[9] Tarantino, A., Gallipoli, D., Augarde, C.E., De Gennaro, V., Gomez, R., Laloui, L., Mancuso, C., El Mountassir, G., Munoz, J.J, Pereira, J.-M., Peron, H., Pisoni, G., 
Romero, E., Raveendiraraj, A., Rojas, J.A.C, Toll, D.G., Tombolato, S. and Wheeler, S. (2011) Benchmark of Experimental Techniques for Measuring and Controlling Suction. Geotechnique, 61, 303-312. https://doi.org/10.1680/geot.2011.61.4.303

[10] Tarantino, A. and Mongiovì, L. (2003) Calibration of Tensiometer for Direct Measurement of Matric Suction. Géotechnique, 53, 137-141. https://doi.org/10.1680/geot.2003.53.1.137

[11] Lourenço, S., Gallipoli, D., Toll, D., Augarde, C. and Evans, F. (2011) Towards a Tensiometer Based Suction Control System for Laboratory Testing of Unsaturated Soils. Geotechnical Testing Journal, 34, 1-10.

[12] Pagay, V., Santiago, M., Sessoms, D.A., Huber, E.J., Vincent, O., Pharkya, A., Corso, T.N., Lakso, A.N. and Stroock, A.D. (2014) A Microtensiometer Capable of Measuring Water Potentials below -10 MPa. Lab on Chip, 14, 2806-2817. https://doi.org/10.1039/C4LC00342J

[13] WP4C (2014) WP4C Dew Point Potentiometer. Operator's Manual. Version June 20, 2014. Decagon Devices, Inc. http://www.decagon.com

[14] Leong, E.-C., Tripathy, S. and Rahardjo, H. (2003) Total Suction Measurement of Unsaturated Soils with a Device Using the Chilled-Mirror Dew-Point Technique. Géotechnique, 53, 173-182. https://doi.org/10.1680/geot.2003.53.2.173

[15] Cardoso, R., Lima, A., Romero, E. and Ferrari, A. (2007) A Comparative Study of Soil Suction Measurement Using Two Different High-Range Psychrometers. Experimental Unsaturated Soil Mechanics, Springer Proceedings in Physics, 112, Springer, Berlin Heidelberg, 79-94. https://doi.org/10.1007/3-540-69873-6_8

[16] Romero, E., Della Vecchia, G. and Jommi, C. (2011) An Insight into the Water Retention Properties of Compacted Clayey Soils. Géotechnique, 61, 313-328. https://doi.org/10.1680/geot.2011.61.4.313

[17] Vanapalli, S.K., Fredlund, D.G. and Pufahl, D.E. (1999) The Influence of Soil Structure and Stress History on the Soil-Water Characteristics of a Compacted Till. Géotechique, 49, 143-159. https://doi.org/10.1680/geot.1999.49.2.143

[18] Jiang, K., Fei, T. and Zhang, T. (2014) Humidity Sensor Using Li-Loaded Microporous Organic Polymer Assembled by 1,3,5-trihydroxybenzene and Terephthalic Aldehydeitle. RSC Advances, 4, 28451-28455. https://doi.org/10.1039/c4ra02763a

[19] Parlange, J.-Y. (1976) Capillary Hysteresis and Relationship between Drying and Wetting Curves. Water Resources Research, 12, 224-228. https://doi.org/10.1029/WR012i002p00224

[20] Van Genuchten, M.T. (1980) A Closed-Form Equation for Predicting the Hydraulic Conductivity of Unsaturated Soils. Soil Science Society of America Journal, 44, 892 898. https://doi.org/10.2136/sssaj1980.03615995004400050002x 
Submit or recommend next manuscript to SCIRP and we will provide best service for you:

Accepting pre-submission inquiries through Email, Facebook, LinkedIn, Twitter, etc. A wide selection of journals (inclusive of 9 subjects, more than 200 journals)

Providing 24-hour high-quality service

User-friendly online submission system

Fair and swift peer-review system

Efficient typesetting and proofreading procedure

Display of the result of downloads and visits, as well as the number of cited articles Maximum dissemination of your research work

Submit your manuscript at: http://papersubmission.scirp.org/

Or contact jst@scirp.org 